\title{
El Discurso Político de José Joaquín Camacho y Lago ${ }^{1}$
}

\author{
The Political Discourse of \\ José Joaquín Camacho y Lago \\ O Discurso Político de \\ José Joaquín Camacho y Lago
}

\author{
Armando Martínez Garnica ${ }^{2}$ \\ Universidad Industrial de Santander - Colombia \\ armandom09@gmail.com
}

Recepción: 09/04/2013

Evaluación: 19/07/2013

Aceptación: 15/05/2014

Artículo de Reflexión

\section{RESUMEN}

Durante el año 1812, el doctor José Joaquín Camacho dirigió al menos 23 cartas políticas al doctor José Fernández Madrid, publicadas en entregas sucesivas del periódico $E l$ Argos Americano y después de la Gazeta de Cartagena de Indias. El destinatario era uno de los editores de esos dos periódicos que se imprimían en la antigua imprenta del Consulado de Comercio, que al publicarlas les fue asignando títulos que daban cuenta de sus temas particulares: comercio del Nuevo Reino de Granada, moneda común de las provincias autónomas, el nuevo sistema general de política interior e internacional, uniformidad de pesos y medidas, riqueza del Reino y urgencia de integrar una federación de sus provincias. Las ideas principales que fueron propuestas en estas cartas políticas ante la opinión pública del Reino por el publicista tunjano fueron cuatro: la necesidad de constituir un pacto de defensa común de las provincias neogranadinas que no obedecían la autoridad de la Regencia, la identificación

1 Este trabajo es resultado del proyecto de investigación "Discursos políticos de criollos ilustrados en las independencias americanas", código SGI: 1128, avalado por el Consejo Superior de InvestigacionesCientíficas (CSIC) y la Universidad Pedagógica y Tecnológica de Colombia. Esta investigación fue desarrollada por el grupo Ilustración en América Colonial (ILAC), reconocido y visible por Colciencias.

2 Doctor en Historia por el Colegio de México. Profesor titular de la Universidad Industrial de Santander, Bucaramanga, Grupo de Investigaciones Históricas sobre el Estado nacional colombiano. 
de la comunidad de intereses comerciales de ellas, la caracterización del intercambio comercial desigual que había existido en el anterior "sistema colonial" y la propuesta de construir una nueva organización política que, partiendo de estados provinciales, formara una federación neogranadina $y$ algún día llegase a una liga de naciones en un congreso continental americano. Se trata del principal legado intelectual de uno de los mayores publicistas ilustrados del proyecto federal y representativo en la Nueva Granada.

Palabras clave: Revista Historia de la Educación Latinoamericana, discursos políticos, José Joaquín Camacho y Lago.

\section{ABSTRACT}

During 1812 Dr. José Joaquín Camacho wrote at least 23 political letters to Dr. José Fernández Madrid. These letters were published in successive deliveries of the Argos Americano newspaper and then in the Gaceta de Cartagena de Indias. The addresse was one of the editors of these two newspapers which were printed in the ancient printing press of the Trade Consulate, who at the moment of being published, the titles were given taking in account their specific topics: Trade of the New Kingdom of Granade, common currency of the autonomous provinces, the new general system of international and domestic policy, evennes of weights and measurement, richness of the Kingdom and urgent need to integrate a federation of its provinces. The main ideas that were proposed in these political letters before the public opinion of the Kingdom by the tunjano publicist were four: : The need to conform a common defense agreement of the neogranadian provinces that did not obey to the authority of the Regency, the community identification of their commercial interests, the characterization of the unequal trade that had existed in the previous "colonial system" and the proposal to build a new political organization that, based on provincial states, it will conform a federation new Granada and someday reach a league of nations in an American Continental Congress. This is the main intellectual legacy of one of the main publishers of distinuished and representative federal project in New Granade.

Key words: Journal History of Latin American Education, political discourses, and José Joaquín Camacho y Lago.

\section{RESUMO}

Durante o ano de 1812, o doutor José Joaquín Camacho remeteu ao menos 23 cartas políticas ao doutor José Fernández Madrid, publicadas em publicações sucessivas do jornal El Argos Americano e posteriormente no jornal da Gazeta de Cartagena de Indias. $\mathrm{O}$ destinatário era um dos leitores desses dois jornais que eram impressos na antiga imprensa do Consulado do Comércio, que ao publicá-las thes foram assinando títulos que davam conta de seus temas particulares: comércio do Novo Reino de Granada, moeda comum das províncias autônomas, o novo sistema geral de política interna e internacional, uniformidade de pesos e medidas, riqueza do Reino e urgência de integrar uma federação de suas províncias. As ideias principais propostas nestas cartas políticas frente à opinião pública do Reino pelo autor foram quatro: a necessidade de construir um pacto de defesa comum das províncias neogranadinas que não obedeciam à autoridade da Regência, a identificação da comunidade de seus interesses comerciais, a caracterização do intercambio comercial desigual que havia existido no anterior "sistema colonial" e a proposta de construir uma nova organização política que, partindo de estados provinciais, formara uma federação neogranadina e algum dia chegaria a uma liga de nações em um congresso continental americano. Tratase do principal legado intelectual de um dos maiores autores ilustrados do projeto federal e representativo na Nova Granada.

Palavras-chave: Revista História da Educação Latino-americana, Discursos políticos, José Joaquín Camacho y Lago. 


\section{INTRODUCCIÓN}

El principal legado político de la Ilustración de José Joaquín Camacho son sus cartas políticas, escritas en Ibagué durante el año 1812 y dirigidas a su amigo José Fernández Madrid, las cuales fueron leídas sucesivamente por la opinión pública que adquiría los periódicos cartageneros. Pero su dispersión no ha permitido a los historiadores una lectura total de su discurso político, si bien está suficientemente establecido su papel como uno de los principales publicistas de la causa de la organización federal que hizo posible la existencia del Congreso de las Provincias Unidas de la Nueva Granada. El general español Pablo Morillo apreció muy bien la importancia política de este reo del delito de infidencia contra Su Majestad, y por ello guardó en su archivo personal toda la correspondencia manuscrita que se le pudo hallar. Es por ello que este artículo se ocupa de presentar el discurso político que se desprende de esas cartas políticas, así como la probable huella de este brillante ilustrado en el primer escudo de las Provincias Unidas. Esta tarea intenta, además, revisar la perspectiva negativa que don José María Salazar (1784-1828) tuvo de las cartas de Ibagué, convencido de que el doctor Camacho había sido un mal político, pues "como estadista tenía el defecto de creer a los hombres tan buenos como él, bello sentimiento para un filósofo, perjudicial para un hombre de Estado". 3

La hipótesis que guía este artículo es la de que el doctor Camacho fue uno de los más brillantes publicistas de la experiencia de la revolución neogranadina, pero que al no haberse reunido y publicado sus cartas de Ibagué, se ha permitido que la historiografía reduzca su importancia e, incluso, que atribuya algunos de sus textos a Francisco José de Caldas, su colega en la empresa de publicación del Diario Político de Santafé de Bogotá (1810-1811). Mediante una lectura cuidadosa de sus escritos dispersos, en buena medida gracias al archivo que llevó a España el general Pablo Morillo, se concluye que su importancia se extiende al texto de la primera carta constitucional del Estado de Tunja, pues su proyecto fue uno de los dos considerados por los diputados ante el Colegio Electoral y Constituyente, y a las acciones políticas del Congreso de las Provincias Unidas de la Nueva Granada. Al fin y al cabo, su vieja experiencia como corregidor de las provincias de Pamplona y del Socorro le había permitido construir una red de corresponsales por todo el Reino, como lo comprueba el interés con que se leyeron sus cartas políticas aparecidas en El Argos Americano y en la Gazeta de Cartagena de Indias.

\section{Comentario del discurso político}

José Joaquín Camacho y Lago llegó a la ciudad de Santa Fe en 1779 para ingresar, como becario, al Real Colegio Mayor de Nuestra Señora del Rosario. Tenía entonces 13 años. Cuatro años después defendió conclusiones sobre varias proposiciones de la Física moderna y en 1784 se hizo bachiller en Filosofía. Continuó en este colegio estudiando los derechos civil y canónico, hasta que en 1788 aprobó el examen que lo convirtió en Doctor en Derecho Canónico por la Universidad Santo Tomás. En este mismo año fue catedrático de Filosofía en su colegio, donde leyó la Dialéctica y la Moral. Dos años después obtuvo el Doctorado en Filosofía y en 1791 fue catedrático de Derecho Público. Terminada su práctica forense en los gabinetes de los abogados Antonio Martínez Recamán y Martín Hurtado, el 16 de enero de 1792 fue recibido

3 José María Salazar y Morales, que escribió la primera biografía del Dr. Camacho, lo pintó como "un hombre lleno de virtudes y un sabio universal", cuyo aspecto y lenguaje lo asemejaban a "un filósofo antiguo, y no se podía ver su aire modesto por el amigo de comparaciones sin figurarse que tal sería Sócrates". Ver "Memoria biográfica de la Nueva Granada, 4, Doctor Joaquín Camacho", Correo del Orinoco, no. 44, 20 de noviembre, 1819. Salazar fue colegial de San Bartolomé desde 1799 y asistente a la tertulia santafereña El Buen Gusto, reconocido poeta y autor de obras de teatro. Era sobrino del licenciado don Juan de Dios Morales, abogado antioqueño que fue dirigente de la Junta de Quito y sacrificado por las tropas peruanas. Desde la perspectiva de Salazar, “las cartas de Ibagué son semejantes a La República de Platón: honran la virtud del autor y harían la desgracia del pueblo con sus bellezas ideales". A pesar de ese presunto utopismo, Salazar reconoció que el Dr. Camacho "fue uno de los que más sostuvieron la Patria". 
por la Audiencia para el ejercicio de la abogacía. Una brillante perspectiva profesional se le abría en el Nuevo Reino de Granada gracias a "su probidad y literatura" y no faltó quien lo recomendara ante el Virrey para un alto cargo administrativo, convencido de que "ocupa el mejor concepto entre los abogados". Relaciones familiares no le faltaban y sus condiscípulos ya comenzaban a brillar tanto en la burocracia virreinal como en el cultivo de las ciencias naturales.

Pero desde el 19 de agosto de 1794 un inesperado acontecimiento perturbó su confianza en la calidad de la real justicia. Dos díscolos estudiantes del Colegio de San Bartolomé, sangileños y primos hermanos - Pablo José de Uribe y Otero y José María Durán Cosío y Otero-, asociados con el cartagenero Luis Gómez y el español José Fernández de Arellano, escribieron y fijaron en varias esquinas una cuarteta para jugarle una chanza a los Oidores de la Audiencia. ${ }^{4}$ Lo que se inició como una broma de tunantes se convirtió en una causa de conspiración contra el gobierno virreinal, llevada por el Oidor Juan Hernández de Alba. Después de habérsele aplicado tormento en el potro al estudiante Durán, la causa terminó en la deportación a España de diez jóvenes ilustrados de las mejores familias del Reino. La reacción de los Oidores fue tan excesiva que llegó hasta el claustro del Rosario, resultando vinculados a la causa algunos de sus catedráticos y estudiantes. Fue entonces cuando Camacho experimentó el deseo de desterrarse "a los montes, a hacer allí una vida solitaria por no sufrir las inquisiciones de los que se decían mis conciudadanos". Efectivamente, el impacto emocional de la causa que formó el Oidor Hernández de Alba en la generación ilustrada que se convertiría en la de la independencia fue muy grande, y por ello ese Oidor fue de los primeros que capturó la plebe en julio de 1810 y remitió con cadenas a la cárcel del Socorro. La memoria de Camacho nunca olvidó ese terrible incidente que conmovió a los catedráticos de los dos colegios mayores del Reino, pues enseñaba a sus discípulos que "el defensor de la justicia debía ser tan puro como el que la dispensa, y que no es lícito ostentar ingenio a costa del derecho que se litiga":

Te acordarás de los sucesos de 1794, en que comenzaron a dejarse ver los primeros rayos de la libertad, y en que tantos de nuestros amigos fueron sepultados en los calabozos y en los cuarteles, bajo estas guardias que pagábamos para nuestra defensa y que solo servían de oprimirno 5 .

El deseo de refugiarse en los montes no fue una simple metáfora, pues efectivamente obtuvo del Virrey Ezpeleta, el 24 de noviembre de 1795, el empleo de teniente de Gobernador letrado de Tocaima, con residencia en la parroquia de la Mesa de Juan Díaz, donde permaneció hasta finales de 1802. La buena fama de su gestión administrativa le valió ante el Virrey Amar y Borbón, que lo nombró el 4 de octubre de 1805 en el cargo de corregidor justicia mayor de Pamplona. El prestigio que había acumulado como hombre ilustrado y brillante abogado se manifestó bien en el año 1809, cuando cinco cabildos del Reino (Antioquia, los Llanos, Socorro, Tunja y Santa $\mathrm{Fe}$ ) lo consignaron en sus ternas para los sorteos que permitirían escoger al diputado del Virreinato ante la Junta Central de España y las Indias.

4 La cuarteta decía: “Si no quitan los Estancos/Si no cesa la opresión/Se perderá lo robado/Tendrá fin la usurpación”. Archivo Histórico Nacional de Madrid (AHNM), Consejos, leg. 21.249 (Santa Fe, 19 de agosto de 1794). Citado por María Clara Guillén, "Pasquines sediciosos en Santafé, año 1794. Documentos inéditos de una conspiración estudiantil”, Boletín de Historia y Antigüedades, no. 853 (jul. - dic., 2011): 270.

5 Carta undécima de José Joaquín Camacho a José Fernández Madrid, "Las sociedades independientes no evitan la destrucción de la especie” (Ibagué, 22 de febrero, 1812), Gazeta de Cartagena de Indias, no. 8, 4 de junio, 1812. 
Durante el año 1812, cuando José Joaquín Camacho permanecía en Ibagué esperando inútilmente la instalación del Congreso de las Provincias Unidas de la Nueva Granada, conforme al Acta de Federación firmada el 27 de noviembre del año anterior, escribió al menos 23 cartas políticas dirigidas al doctor José Fernández Madrid, las cuales fueron publicadas en entregas sucesivas del periódico El Argos Americano y después de la Gazeta de Cartagena de Indias. El destinatario era uno de los editores de esos dos periódicos que se imprimían en la antigua imprenta del Consulado de Comercio, que al publicarlas les fue asignando títulos que daban cuenta de sus temas particulares: "Comercio del Nuevo Reino de Granada", "Moneda común de las provincias autónomas", "El nuevo sistema general de política interior e internacional", "Uniformidad de pesos y medidas", "Riqueza del Reino y urgencia de integrar una federación de sus provincias".

Las ideas principales que fueron propuestas en estas cartas politicas ante la opinión pública del Reino por el publicista tunjano fueron cuatro: la necesidad de constituir un pacto de defensa común de las provincias neogranadinas que no obedecieran la autoridad de la Regencia, la identificación de la comunidad de intereses comerciales de ellas, la caracterización del intercambio comercial desigual que había existido en el anterior "sistema colonial" y la propuesta de construir una nueva organización política que, partiendo de estados provinciales, formara una federación neogranadina y algún día llegase a una liga de naciones en un congreso continental americano. Se trata del principal legado intelectual de uno de los mayores publicistas ilustrados del proyecto federal y representativo en la Nueva Granada, cuyo lugar en la alta dirigencia del Congreso de las Provincias Unidas tuvo que pagar con su vida en los tiempos de la restauración del dominio de la monarquía. Enseguida se detallarán esas cuatro ideas principales del discurso político del doctor Camacho.

\section{Pacto de defensa común de todas las provincias}

Las primeras cuatro cartas políticas fueron publicadas, durante los tres primeros meses de 1812, en El Argos Americano, un "papel político, económico y literario" que publicaban en Cartagena José Fernández Madrid y Manuel Rodríguez Torices. Desde el prospecto (10 de septiembre de 1810), estos dos publicistas habían convocado a "los literatos del Reino" a "honrar e ilustrar a su patria, que tanto lo necesita", remitiendo sus nuevas ideas y sus conocimientos en papeles, francos de porte, por la valija del correo hacia Cartagena. En la "crisis peligrosa" en la que se encontraba el Nuevo Reino de Granada tras la erección de juntas de gobierno provinciales, con la disolución del gobierno superior que residía en Santa Fe, nada convenía más que "uniformar las ideas", y para ello habían nacido los nuevos papeles periódicos, los conductores más seguros para comunicar las ideas y para "fijar la opinión pública". ${ }^{6}$ Camacho convocó en esas primeras cuatro cartas políticas a los pueblos de las provincias del Nuevo Reino de Granada, que se estaban organizando como estados provinciales, a la organización de una defensa común contra cualquier ataque militar de los enemigos del proceso que se había iniciado, argumentando que ello exigía poner en común todos sus recursos humanos y financieros, pues la destrucción de una sola de las provincia neogranadinas por las fuerzas de la Regencia amenazaría la existencia de las demás. Era preciso entonces que concertaran un pacto de defensa común fundado en una federación de estados provinciales, tal como se había firmado en el Acta de federación a finales de noviembre del año anterior:

Amigo: seguiré hablándote de aquellos puntos en que se acuerdan, y en que no se pueden dividir los intereses de los diversos Pueblos que habitan este Reino. Ya hemos

6 Prospecto: “Papel político, económico y literario de Cartagena de Indias", El Argos Americano, 10 de septiembre, 1810. 
visto que a todos interesa igualmente la defensa común, para cuyo logro deben reunir todos sus recursos, no pudiendo padecer una destrucción ninguna de las Provincias Unidas sin que se vea amenazada la existencia de todas las otras. El pacto que las reúne para repeler estos peligros las hace insensibles, dándoles una firmeza que no tendrían si se mantuviesen aisladas en lo que concierne a este objeto. Tenemos, pues, un lazo que une los distintos Estados que deben componer la federación, cuya independencia parcial se disminuye cuanto más se multipliquen estos puntos de contacto.?

\section{Comunidad de intereses comerciales de los pueblos de la Nueva Granada}

El pacto de defensa común de las provincias tendría que ser complementado con una resolución pacífica de las diferencias comerciales entre los estados provinciales que adhirieran al Acta de federación. El mal ejemplo de las guerras que se habían dado entre algunos estados europeos por la disputa de algún canal navegable tendría que ser conjurado. Para ello, debería erigirse algún poder superior capaz de remover los obstáculos que dificultaban la libre circulación de las mercancías en el interior del Reino, tal como un tribunal formado por el congreso general de los estados que se unieran en la federación.

El comercio exterior también tendría que ser responsabilidad de este congreso de los estados provinciales unidos, pues velaría por la seguridad de los puertos y la navegabilidad de los ríos. También representaría a los estados federados donde quiera que se establecieran tratados comerciales con los estados de América y Europa, concediendo libertad a cada uno de los estados particulares para promover sus industrias particulares, el cultivo de sus producciones, sus exportaciones y la introducción de lo que necesitasen para su provisión. Esta concertación de la federación con los estados particulares para la promoción de sus intereses comerciales era una ventaja sobre los regímenes estatales centralizados:

... el gobierno general y los particulares proceden de concierto y conspiran a un mismo fin, sin que choquen en sus operaciones, cesando la acción de éstos donde comienza ya a interesarse el bien general de las provincias. ¿Hay quejas en lo tocante a la industria entre los artistas de un estado particular? Su Gobierno las debe componer sin que se mezclen los tribunales de la Unión. ¿Las disputas son sobre agravios hechos al comercio de un estado en el interior de otro estado? La decisión corresponde a un tribunal donde tengan igual parte los dos estados que controvierten. ${ }^{8}$

Los regímenes centralizados tenían el grave defecto de concentrar las decisiones en un solo lugar, "siendo los recursos distantes lo más penoso para los pueblos, que muchas veces sufren el mal más bien que ocurrir por un remedio incierto a un lugar distante".

El comercio interior del reino tendría que ser libre "para que derrame la abundancia y lleve la prosperidad a todas partes". Liberado de las aduanas interiores, se eliminarían las guías y registros que obstaculizaban la circulación mercantil en el régimen anterior. Todas las provincias deberían concordar en la conveniencia de la libre y rápida circulación mercantil, eliminando todos los gravámenes que pesaban sobre el ingreso de las mercancías. Las exportaciones hacia fuera del reino también deberían liberarse como una manera de fomentar la agricultura, y los derechos de importación deberían ser los mismos para todos los estados.

\footnotetext{
$7 \quad$ Carta quinta: "Que en el comercio externo se versa el interés general de las Provincias" (Ibagué, 16 de enero, 1812), Gazeta de Cartagena de Indias, no. 3, 30 de abril, 1812.

8 Carta quinta citada en Gazeta de Cartagena de Indias, no. 3, 30 de abril, 1812.
} 
Las aduanas de los puertos deberían ponerse bajo la inspección del Congreso de las Provincias Unidas, pues se trataba de la principal fuente de rentas para el financiamiento de sus gastos, y los ingresos aduaneros de las importaciones también debían ser exclusivamente para ese ente. Esos derechos de entrada y salida de mercancías había que entenderlos como "contribuciones indirectas que recaen sobre los consumidores que están esparcidos por todo el Reino", y por ello deberían entrar a la hacienda federal, como "cualquiera contribución que no emane determinadamente de los habitantes de cada provincia en particular".

Esta idea de Camacho es interesante: quizás teniendo a la vista la tradición anglosajona - "no Taxation without Representation" -, opinaba que los impuestos directos irían a las respectivas haciendas de los estados provinciales, cuyas legislaturas aprobaban los impuestos director sobre sus ciudadanos, mientras que los impuestos indirectos heredados del Estado monárquico irían a la hacienda federal. Por ello, las ganancias que provenían de la ley que se daría a las monedas de plata y oro que circularían en el Reino, al ser de origen indirecto, pasarían a la hacienda federal. Los antiguos monopolios que pesaban sobre los aguardientes y los tabacos, como contribuciones indirectas cargadas sobre el consumo, también deberían ser para la hacienda del Congreso. De todos modos, Camacho advirtió sobre la responsabilidad fiscal que pesaba sobre el Congreso respecto de los ciudadanos:

Son poco gravosas al todo de la sociedad las contribuciones bien dirigidas que se hacen para fines justos, y que han de restituir prontamente a los pueblos que las hacen. Supongo que el Congreso tuviese que gastar para abrir caminos, construir puentes, hacer los ríos navegables, y otras obras en que se interesase la gran familia. ¿No es cierto que serían mayores las ventajas que el Reino sacaría de estas obras que proporcionaban proveerse a menos costo de los géneros que necesitase para su consumo, que las cargas tal vez momentáneas que tendría que sufrir para obtener estas comodidades? ¿No aumentaría también considerablemente el valor de sus frutos, facilitándose su exportación ${ }^{10}$

A pesar de la fertilidad de las tierras del Reino, apenas se cultivaban cantidades pequeñas de frutos necesarios para que los granadinos no muriesen de hambre, todo porque no existían caminos ni canales de navegación, ni menos puertos que comunicaran con las naciones industriosas y comerciantes. Como dirigente del nuevo orden que se iba a instaurar, se atrevió a ofrecer la solución a estos obstáculos del comercio internacional con la buena administración de los impuestos estatales:

¡Pueblos de Bogotá!, no temáis las contribuciones que hagáis en vuestro beneficio, y que son anticipaciones para traer las riquezas. Ya no contribuís para alimentar tropas que os mantengan en las cadenas, magistrados que os vendan la justicia, Gobernadores que solo trataban de juntar grandes tesoros para irlos a gozar a su país, príncipes y favoritos que holgaban en mullidos lechos, mientras que vosotros trabajabais al rayo del sol cavando las minas que debian suministrar el precioso oro para adornar a sus concubinas. ${ }^{11}$

9 Esta famosa expresión fue usada por el reverendo Jonathan Mayhew en un sermón que pronunció en Boston durante el año 1750, pero, por lo menos, una generación antes ya se había divulgado en Irlanda. Cinco años después ya era moneda corriente en Boston, modificada por el político local James Otis en términos más radicales: "Taxation without Representation is tyranny".

10 Carta sexta: "Derechos de entrada y salida. Que los productos de la moneda que circula en el Reino deben ser comunes" (Ibagué, 22 de enero, 1812), Gazeta de Cartagena de Indias, no. 3, 30 de abril, 1812.

11 Carta sexta citada en Gazeta de Cartagena de Indias, no. 3, 30 de abril, 1812. 
El tema de la conversión de las onzas de oro en monedas de plata en el nuevo orden republicano avivó su diálogo con Fernández Madrid. Antes de la revolución se daban 16 pesos de plata por una onza de oro de 22 quilates, y ahora se daba lo mismo pero por onza de ley menor, 21 quilates. Fernández Madrid infería que si ahora se compraba la misma cantidad de ropas o de géneros que antes con los 16 pesos de plata, eso significaba que el valor intrínseco del oro se había depreciado. Camacho discrepó de esta interpretación en los siguientes términos:

Yo creo que, si todos calculasen, no habría ya, desde que se bajó la ley a la moneda de oro, quién la recibiese por su valor nominal, habiéndose alterado la proporción que antes había de la moneda de oro a la de plata; pero seguramente los cambistas darán menos premio por el oro, que el que dieran si retuviese su antiguo valor intrínseco, y lo mismo, como dije, los que venden en grande para llevar el oro a las naciones extranjeras. Los que reciben el premio del oro, y los que venden géneros exportables son, pues, los que pagan en últimas la contribución que resulta de los menos quilates que se dan al oro. ${ }^{12}$

En opinión de Camacho, se trataba de una exacción generalizada que no debería tolerarse más. Para ello, el gobierno federal debería ordenar a todas las provincias una determinación uniforme de la ley del metal, que en la práctica significaba la apertura de una nueva casa de moneda federal, distinta a las dos legadas por el régimen anterior en Santa Fe y Popayán, capaz de "monopolizar la fabricación de moneda para sacar de ella grandes ganancias". Vaticinó que las dos antiguas casas de moneda tendrían que dar paso a una sola casa general de acuñación de monedas, porque la competencia entre varias tendería a reducir el costo de la acuñación a solo el valor de la mano de obra empleada, con lo cual las ganancias de los fabricantes se reducirían al mínimo y el Estado ya no obtendría los anteriores aprovechamientos. La experiencia de 19 meses de revolución aconsejaba promover el establecimiento de una escuela de Economía Política y otra de Derecho Público, pues la tradición legada de "ciega obediencia" y de "tiranía" había sumido en la oscuridad los derechos del hombre.

Camacho también aconsejó la uniformización de los pesos y las medidas en todo el territorio americano, una reforma que ayudaría al "adelantamiento de las ciencias exactas, cuyos progresos se retardan manifiestamente por la dificultad de las reducciones numéricas", pero sobre todo a su utilidad económica:

¡Cuánto influiría para la facilidad y multiplicación de los cambios, giro de las correspondencias, misión política de las naciones, que por todas ellas se usasen unas mismas medidas que presentasen ideas justas de los valores de las tierras, y demás efectos comerciales! [...] Hará siempre honor a la Francia la invitación que hizo a las naciones europeas para que concurriesen por medio de diputados a fijar medidas comunes que sirviesen en todo el antiguo continente, y aunque aquella empresa no haya tenido todo el efecto que se deseaba por las guerras en que la Europa ha sido envuelta, no por eso prueba menos la necesidad de una convención general para la resolución de los asuntos en que se interesan las diversas naciones. ${ }^{13}$

12 Carta séptima: "Sigue hablando sobre la ley de la moneda" (Ibagué, 28 de enero, 1812), Gazeta de Cartagena de Indias, no. 5, 14 de mayo, 1812.

13 Carta decimoquinta: "Uniformidad de pesos y medidas" (Ibagué, 18 de marzo, 1812), Gazeta de Cartagena de Indias, no. 14, 16 de julio, 1812. 
De nada serviría conocer el valor de una fanegada de tierra rural si en todas las partes de América no existiera un acuerdo unánime respecto de su extensión. En América, las medidas y los pesos variaban de reino a reino, de provincia a provincia y de localidad a localidad. En adelante, deberían estar regulados los pesos por prototipos nacionales, pero también se debería organizar una convención de diputados de todos los países europeos, tal como había propuesto Francia que resolvería este obstáculo que enfrentaba el comercio internacional. Aunque la uniformidad del idioma facilitaría la realización de este propósito en la América española, era también necesaria la organización de un congreso continental para lo mismo, pues los americanos del sur deberían fundir sus costumbres con los americanos del norte, "mucho más adelantados en ciencias y artes", ya que desde 1792 estos habían introducido los números decimales en su sistema monetario y en su sistema contable.

\section{Intercambio comercial desigual del "sistema colonial"}

Entusiasmado con la perspectiva de la transformación comercial que prometía la revolución, Camacho le confió a su corresponsal cartagenero unos cálculos sobre el desigual intercambio comercial que, en su opinión, había regido al Reino antes de 1810, fuente de lo que los nuevos publicistas ya calificaban en términos de "sistema colonial". La precocidad con la que este publicista tunjano introdujo este concepto en el debate político de su tiempo sorprende, pues hasta nuestros días los publicistas contemporáneos siguen usándolo con sus connotaciones morales, ya que su fundamento es una supuesta "injusticia" que no tenía otro objeto que "hacer miserables infinitos pueblos para engrandecer a otros que se decían sus tutores". Antes de comenzar su caracterización de esa "injusticia", Camacho confió a Fernández Madrid su cometido ideológico: "Amigo ... Mi alma se dilata entre los dos términos de nuestra transformación política; considera lo que hemos sido, y lo que vamos a ser; busca entre los escombros del antiguo edificio las causas que influyeron en su destrucción, y que nos importa conocer, para levantar el nuevo sobre bases más duraderas". ${ }^{14}$

El supuesto de la caracterización de la injusticia del régimen comercial anterior partía del principio según el cual todo país del mundo tiene derecho a retener sus producciones propias, las cuales no deberían salir de su territorio a menos que fuesen reemplazadas con otras equivalentes. Siempre que algún pueblo fuese obligado a dar sin recibir algo a cambio, se seguía necesariamente de ello que comenzará a "desfallecer en la miseria":

No porque un país sea demasiado rico, tienen derecho los otros al sobrante de sus adquisiciones, ni de enriquecerse a costa ajena. Su fecundidad no le serviría entonces sino de carga en favor de otros pueblos menos activos, o cuyo país fuese más estéril. ¿Por qué especie de injusticia hay algunos países como consagrados a la ambición y voracidad de otros? ¿Por qué razón los pueblos de Europa se creen con derecho a las producciones de la América, que llaman su patrimonio? Todos los países de la tierra retienen su sustancia: solo los nuestros dan lo que es suyo sin alguna compensación. ${ }^{15}$

Las exacciones financieras de América habían tenido varias fuentes: funcionarios españoles que venían temporalmente a ocupar cargos públicos y luego se marchaban a otros países "con todo el fruto de sus depredaciones", con lo cual "nuestra sangre civil manaba continuamente para otros reinos, sin que estas enormes pérdidas se reparasen por algunos medios". Los

\footnotetext{
14 Ibíd. Carta XXIII, “Riqueza del país”, Ibagué, 4 de septiembre, 1812, Gazeta de Cartagena de Indias, No. 53, 15 de abril, 1813 y No. 54, abril, 1813

15 Ibíd.
} 
mismos americanos remitían caudales a la Corte para comprar empleos que "se vendían descaradamente, sin atender al mérito de los que debían ejercerlos"; todos los años se remitían caudales para el sostenimiento de los conventos ultramarinos, pues era este el modo como "nuestros pobres religiosos" obtenían sus "grados y privilegios". En síntesis, de España venían "gracias, títulos y honores que no costaban nada y que a nadie dan que comer; de aquí debían ir los metales y nuestros frutos más preciosos".

Pero la mayor exacción era el intercambio comercial desigual, cuya operación permitía hablar de un "comercio colonial", un concepto también introducido precozmente por Camacho para sintetizar la siguiente imagen de su funcionamiento:

Los géneros que fabricaban los franceses e ingleses los tomaban en la Peninsula, donde les cargaban de contribuciones que debiamos pagar con la muy crecida ganancia que hacian las manos españolas en las multiplicadas ventas que ejecutaban para que llegasen a los consumidores americanos ... Si las manufacturas extranjeras nos hubieran venido directamente de manos de las naciones industriosas nos hubieran costado un veinticinco por ciento menos de los que nos constaban pasando por las Aduanas de Cádiz; y más de un setenta y cinco por ciento de la ganancia que hacian sobre ellos los comerciantes españoles. ${ }^{16}$

Si el comercio anual del Nuevo Reino de Granada se transaba con tres millones de pesos; resultaba que si sus puertos hubiesen estado abiertos a los navíos de las naciones extranjeras hubiera podido transarse con la mitad de esa cantidad de pesos, con lo cual podía decirse que el millón y medio que se obtenía por el monopolio comercial español "se nos extraía sin ninguna compensación". Al suponer que todo el oro extraído de las minas del Reino montara anualmente tres millones, resultaba entonces que la mitad del trabajo de "nuestros mineros se nos robaba por medio de este monopolio".

Algo similar sucedía con las exportaciones del Reino, pues eran sacadas por la mitad de su justo valor gracias a la limitación de la concurrencia de compradores de todas las naciones, una operación que explicaba las grandes ganancias que hacían los comerciantes en las plazas de Cádiz y Barcelona con la venta de las quinas y demás frutos "coloniales" revendidos a los comerciantes extranjeros. Estas ganancias les correspondían "en ley y en conciencia" a los neogranadinos, pues si hubiese existido libertad de comercio en sus puertos, habrían podido vender a mejores precios sus mercancías. El monopolio comercial había sido entonces una "gravísima injuria no solo contra los americanos, sino contra todas las naciones de la tierra, que tienen derecho a expender sus frutos en estas regiones y proveerse de lo que ellas producen por medio de pactos con sus naturales".

Frente a esta grave injuria había que romper las ligaduras con que "la ambición española" había atado el comercio exterior del Reino, llamando a los americanos a participar de los beneficios que ofrecía la naturaleza en el Nuevo Mundo, pero también a todos los habitantes de la tierra que tenían derecho, no menos que los españoles, a contratar con sus semejantes y beneficiarse de sus industrias. Por un común interés del género humano y por medio de una sana política y de correspondencias nacionales, América debía elevarse "a aquel punto de cultura a que la llaman sus grandes proporciones, multiplicándose sus riquezas y esparciéndose con un justo equilibrio para el consumo de las demás naciones", pues hasta entonces había sido privada de la abundancia por las trabas que había inventado la tiranía.

16 Ibíd. 
El inventario de las "usurpaciones" fue completado por Camacho con las contribuciones extraordinarias que la Corona pidió para el sostenimiento de las guerras que libró contra otras potencias europeas, otra "injusticia" porque, en su opinión, había involucrado los intereses americanos con la defensa de intereses particulares. La guerra contra Inglaterra fue blanco de sus reproches, no solo porque privó a los puertos de la Nueva Granada de un comercio directo con los navíos ingleses, "que solo podría enriquecerla contra las usurpaciones del monopolio", sino porque había sido fuente de nuevas contribuciones: venta de bienes de las fundaciones piadosas, recaudo de donativos extraordinarios por emisarios enviados, etc. Cualquiera que fuese el resultado de esas guerras, "la América siempre perdía", pues "a nosotros qué nos importa defender un monopolio tan opuesto a los nuestros". Si Inglaterra, la "nación señora de los mares", estaba dispuesta a proveer lo que este Reino necesitaba a precios más bajos, "esto nos es más ventajoso que la humillación de este poder".

Pasó entonces Camacho a calcular el intercambio comercial desigual que se había producido en el Nuevo Reino de Granada:

El comercio de importación, que se transaba con tres millones, se podía haber transado con la mitad menos, suponiendo el libre comercio a nuestras costas, 1.500.000. Medio millón que se regula remitirse anualmente del tesoro público, 500.000. Otro tanto que llevarian los empleados que volvian a España, incluyéndose las cantidades que se remitían continuamente para las pretensiones, gratificaciones, por las gracias que se nos hacian etc., 500.000. Las rentas que se llevaban todos los años a España de las capellanías y mayorazgos fundados en favor de los peninsulares, que según el orden natural se debian mantener de los frutos de su propio país ... Resulta que anualmente se sacaban de este pobre Reino dos millones y medio de pesos, sin compensación alguna. ${ }^{17}$

Si esos 2.500.000 pesos se hubiesen empleado durante el año siguiente en promover la agricultura, por lo menos en una tercera parte se hubiera incrementado este capital, y así cada año se hubiera seguido la acumulación.
¡Qué incremento no hubieran tomado estas! ¡Cuántos matrimonios se hubieran hecho con la esperanza de sustentar los hijos! ¡Cuán rápido aumento hubiera tomado la población! ¡Cómo hubiera florecido nuestro comercio y artes! Todos hubiéramos tenido qué comer en lugar que hasta la presente se puede asegurar que la mayor parte de los nacidos en este reino mueren de inacción, a pesar de la inmensa extensión y fecundidad inagotable del país. Creo que poco más, o menos esta es la suerte de las demás colonias españolas, que por todas partes presentan la imagen de la muerte y desolación. ${ }^{18}$

\section{Sistema general de política y organización de federaciones de estados}

La convicción de la abierta injusticia con la que la Monarquía española había organizado el comercio internacional con sus "colonias" condujo a Camacho a imaginar, partiendo del suceso revolucionario de 1810, el modo de "montar una máquina política compuesta de muchas ruedas que, casando unas con otras, se gobernasen todas y conservasen sus centros en virtud de un primer móvil que mantendría la armonía universal". Era el sueño de un justiciero ambicioso, y esa fue la fuente de su actividad como publicista revolucionario al

17 Carta XXIII: "Riqueza del país" (Ibagué, 4 de septiembre, 1812), Gazeta de Cartagena de Indias, no. 53, 15 de abril, 1813

18 Ibíd., no. 54. 
servicio de la federación de las provincias neogranadinas. Propuso, entonces, en la octava y novena cartas políticas, que su destinatario cartagenero tituló "Sistema general de política", la composición de sociedades de sociedades que harían posible la realización de una situación en la que "la justicia reinará por toda la tierra y se cerrará para siempre el Templo de Juno":

\section{¿Si estará reservado a la América dar la primera el ejemplo de esta organización general, poniendo los fundamentos del sistema magno que debe poner las cosas en su verdadero estado, sacándola del caos en que han estado sumergidas? El mundo moral no es como el físico, cuyas grandes masas mantienen casi siempre su equilibrio, y describen los círculos por fuerzas invariables. En lo moral se encuentra más agitación y acaso este movimiento perturbado era necesario para que las partes se colocasen con el orden debido en fuerza del desarrollo a sus mismas facultades. ${ }^{19}$}

Esa nueva organización política del mundo debía partir de los distritos locales —el gobierno inmediato de todas las familias en cada lugar determinado- y mediante la reunión de esos distritos se pasaría a conformar los gobiernos provinciales, entendidos como una especie de "pequeños estados". Sucesivamente, las provincias se reunirían en federación para construir las naciones, y estas en su actuación internacional podrían llegar a la formación de ligas de naciones. Siguiendo ese mismo orden político, la nueva organización de justicia partiría de los juzgados distritales, y sus fallos pasarían en otra instancia a recurrir ante tribunales provinciales, hasta que finalmente se resolverían todos los recursos en un tribunal general de la nación. Este proyecto de organización política sacaría a las naciones del "estado natural" en que se hallaban, para conducirlas a un "estado de civilización", de la misma manera que los individuos que compondrían estas naciones no sacarían ventaja alguna de su asociación si los intereses comunes se hubiesen de decidir por la suerte de las armas. En cualquier caso, estas asociaciones se formarían libremente y adoptarían un régimen federal, pues así como el recaudo de las contribuciones de los ciudadanos tendrían que repartirse, en justicia, entre la satisfacción de las necesidades de las provincias y la de las necesidades comunes para el bien general y la protección frente a los enemigos exteriores, una centralización a la antigua era una gran injusticia y exacción gravosa a los pueblos. Las ligas de naciones les permitirían decidir pacíficamente sus contiendas, superando un pasado de estado continuo de guerra.

Frente al escepticismo que ponía en duda la conjuración de guerras entre las naciones, Camacho recordó que las guerras europeas del pasado no la habían hecho los pueblos sino "cortos números de individuos que por sus intereses particulares sacrifican los pueblos". El terrible cuadro histórico de Europa, "que en treinta siglos no presenta sino calamidades, guerras, desolación", había que seguir el consejo de uno de sus oráculos: "Evitad, nos dice, tardad a lo menos, en entrar en las pasiones del antiguo hemisferio. No toméis de su vejez sino sus luces." Terminada la época de la tiranía, en el Nuevo Mundo estaba naciendo un orden más justo y racional, lo cual obligaba a empeñarse para construirlo en el Reino: "Oigo una voz que sale de los cuatro ángulos de la América, y que nos persuade que abracemos el sistema fraternal de gobierno, que tan felizmente ha comenzado a establecerse en el nuevo Mundo. Reprimid, ciudadanos, cualquier conato que veáis dirigirse a establecer el despotismo sobre nosotros"..$^{20}$

El proyecto de liga de las naciones fue acariciado por Camacho, convencido de sus bondades para el proceso de civilización que prometía el Nuevo Mundo frente a Europa:

19 Carta octava: "Sistema general de política” (Ibagué, 4 de febrero, 1812), Gazeta de Cartagena de Indias, no. 6, 21 de mayo, 1812

20 Carta nona: “Continúa el mismo asunto” (Ibagué, 10 de febrero, 1812), Gazeta de Cartagena de Indias, no. 6, 21 de mayo, 1812. 
Esta no es una invención que se nos deba, sino un paso adelante que hemos dado en el sistema federativo y representativo, que con tan buen suceso han adoptado los angloamericanos. Los principios en que se funda aquel Gobierno son en 'todo' y por todo adaptables a la gran federación que proponemos. Lo que es el congreso federativo a los Estados Unidos, de que resulta será el Congreso universal respecto de las Naciones Unidas. Sabidas las leyes que gobiernan las federaciones particulares, se sabe las que deben regir la asociación general que se funda sobre ellas. ${ }^{21}$

En la nueva "máquina política" imaginada, las "primeras ruedas" eran los estados provinciales que retenían su gobierno y administración interiores, pues apenas cederían al congreso federal las facultades relativas a los negocios generales de la nación. Del mismo modo, los estados nacionales que habían sido integrados federalmente por los estados provinciales retenían en sí la dirección general de ellos, pero cederían al Congreso Universal solo las facultades dirigidas al arreglo de los asuntos particulares que interesaban a la mayoría de las naciones respecto de las otras. Para "cerrar la bóveda del edificio" político universal, sería necesario establecer un centro común a todas las naciones, donde concluirían los negocios que corrían entre las naciones, una autoridad que nunca antes se había constituido para tomar esas decisiones. El "cuerpo supremo" de todas las naciones ligadas no solo resolvería los negocios comunes por las vías de la justicia, sino que además formaría un "código de derecho de gentes" hasta entonces desconocido en el mundo. Serían entonces del resorte de esta "Asamblea Legislativa" multinacional todas las disposiciones comunes de comercio, marina, guerra y todos aquellos asuntos que antes se concluían por medio de tratados particulares entre naciones. No sería esta una asamblea de reyes, como la que había visto en Roma el embajador de Pirro, sino "el cuerpo de la concordia y de la paz, donde se dé cruda muerte a todas las disensiones políticas que han costado tan caro a la humanidad". Inspirado en sentimientos de humanidad, Camacho convocó a todas las naciones a transitar por el camino de la pacificación de las costumbres políticas:

Convéngase las distintas federaciones que se formen en América en dirigir sus enviados a cierto punto, con poderes suficientes para celebrar esta alianza eterna, redactar ellos mismos la Acta Suprema de Unión que después han de ratificar los congresos nacionales, y todo será hecho con la facilidad que promete una empresa dictada por el amor a la justicia. Yo convido a las naciones de la tierra a que dejen las costumbres feroces que han tenido hasta aqui, a que se gobiernen según las máximas de la sabiduría, que renuncien para siempre a la bárbara y fantástica gloria de las conquistas, y que no conozcan otros héroes sino los que aman la paz y tranquilidad de los pueblos. ${ }^{22}$

Antes de que se formase esta liga de naciones, era preciso convertir los dominios americanos de la monarquía española en federaciones de estados provinciales. Recordó que los reyes habían dividido a América en grandes unidades políticas, independientes unas de otras, llamadas virreinatos y Capitanías generales, que se ligaban directamente con la metrópoli. Cada uno de estos gobiernos superiores era ejercido "despóticamente" por un jefe militar y por magistrados supremos, con lo cual apenas mantenían una "aparente subordinación a la Corte de Madrid". Pues bien, en cada una de esas grandes unidades políticas, se deberían formar en adelante gobiernos federales, integrados por pequeños estados que se organizarían en cada

\footnotetext{
21 Carta duodécima: “Se explana el proyecto de Unión de las Naciones" (Ibagué, 28 de febrero, 1812), Gazeta de Cartagena de Indias, no. 9, 11 de junio, 1812. La siguiente cita textual en este epígrafe proviene de esta misma carta.

22 Ibíd.
} 
una de sus antiguas provincias, "según la voluntad general que todas ellas han manifestado de darse esta forma de gobierno". Bajo un gobierno federal, las provincias-estado juntarían todos sus recursos y harían un solo cuerpo para afrontar los peligros de una guerra exterior. Estas federaciones americanas, libremente constituidas, lo harían según los principios "de una eterna justicia", y por sí mismas se harían respetar de todos los gobiernos del mundo, para lo cual podrían ligarse entre sí por medio de un congreso continental, el mejor medio para precaver cualquier invasión sobre algún lugar del continente. Aunque los nuevos gobiernos americanos, ocupados en sus propios peligros, no podían prestarse aun sus auxilios, era posible en el futuro, una vez que sacudieran de su seno "los agentes de la tiranía", unir sus fuerzas en un congreso continental contra cualquier intento de opresión exterior.

Camacho creía que "todas las provincias de la Nueva Granada" habían "gritadouniformemente que conviene a su prosperidad adoptar el sistema federativo". Todos debían obedecer esa "sanción soberana del pueblo que parte de la voluntad general". Frente a quienes aconsejaban la reunión de todas las fuerzas y recursos en un único centro con gobierno absoluto, replicó que los grandes cuerpos centrales, dotados con facultades omnímodas, eran "masas inertes" fáciles de dominar fácilmente en las que el depositario del poder ejecutivo, revestido con facultades absolutas, terminaba por disolver los cuerpos centrales que daban las leyes. La revolución de Francia era el mejor ejemplo de ello, pues "el pueblo más entusiasta de la libertad" terminó "tiranizado por haber querido establecer un cuerpo central representativo de todos los departamentos de aquella gran nación". Esta posición política convirtió a Camacho en uno de los más decididos opositores al mando de Antonio Nariño sobre el Estado de Cundinamarca, quien desbordó con su dictadura los peores vaticinios sobre su conducta:

Tales son, mi querido amigo, los fines que se han propuesto los que quieren despojar a los Pueblos de sus más justos derechos, y que aspiran por medio de maquinaciones astutas y pérfidas a destruir los Gobiernos populares para ser ellos solos los caudillos, y devorar a su salvo la sustancia de los demás hombres. Nuestro deber es atacar estos genios enemigos de la libertad, poner a las claras sus engañosas artes y trabajar con todas nuestras fuerzas en beneficio de la humanidad que ellos persiguen. ${ }^{23}$

El Congreso de las Provincias Unidas de la Nueva Granada, pese a las discordias "que fomentan ciertos espíritus enemigos del orden", era "la primera piedra del grande edificio" que meditaron Camacho y Fernández Madrid. La comparación con las realizaciones del Congreso de las Provincias de Venezuela era inspiradora: "Cuánto debemos envidiar la suerte dichosa de los caraqueños, que guiados por los consejos de los Burkes, Ustáriz y Roscios han logrado organizar su gobierno, colocándose en una posición respetable, que pone en desesperación a sus enemigos, y que bien presto hará reconocer su independencia de las naciones europeas" ${ }^{24}$ El Acta de Federación que fue firmada el 27 de noviembre de 1811 por los diputados de cinco provincias (Antioquia, Cartagena, Neiva, Pamplona y Tunja), entre ellos el mismo Camacho, era esa "primera piedra" mencionada, pero aún no había sido posible reunir el Congreso General de las Provincias del Nuevo Reino para que cumpliese efectivamente el propósito de federación:

23 Carta decimosexta: "Importa que cuanto antes se formen las federaciones americanas" (Ibagué 24 de marzo, 1812), Gazeta de Cartagena de Indias, no. 15 y 16, julio 23 y 30, 1812.

24 Carta decimoquinta citada en Gazeta de Cartagena de Indias, no. 14, 16 de julio, 1812. Se trata de Francisco Javier Ustáriz, William Burke y Juan Germán Roscio, personajes significativos para los publicistas neogranadinos. El irlandés Burke había publicado en la Gazeta de Caracas (23 de noviembre de 1811) una serie de reflexiones tituladas “Derechos de la América del Sur y México", de amplia resonancia en la Nueva Granada, reimpresas en el Diario político de Santafé de Bogotá (1812). Lo mismo sucedió el texto de Roscio titulado Patriotismo de Nirgua y abuso de los reyes. 
Sólo falta que nos demos prisa en consumar esta grande obra, y que presentemos al mundo estas grandes masas organizadas que se llaman naciones, sin otro título que el de formar gobiernos separados bastándose a sí mismas en todas sus necesidades políticas. Sería un absurdo que se tratase de reconcentrar en si misma una pequeña provincia que no pudiese figurar entre los grandes Estados, y que por más recursos que tuviese fluctuaría siempre en la incertidumbre expuesta a ser engullida por los Estados que la rodeasen. Es indispensable dar a nuestras sociedades la fuerza y robustez que necesitan para conservarse en medio de las agitaciones que pueden turbar nuestro hemisferio, y para resistir a las empresas ultramarinas que se intentan contra nosotros. Mientras los Estados Unidos de América no vean que nos ponemos en esta situación firme y denodada es un delirio pensar en que reconozcan la existencia de unos gobiernos zozobrantes, que perderían muy pronto la forma que hubiesen querido tomar. $^{25}$

Camacho propuso formar distintas federaciones americanas, pronosticando que posteriormente se ligarían en un congreso continental de mutua defensa (armas, dinero, tropas), con lo cual se harían respetar de todos los gobiernos del mundo. El tamaño de la federación neogranadina sería el siguiente:

Veinte y dos provincias colocadas sobre un espacio de setenta y seis mil leguas cuadradas, que reúnen por su situación las mayores ventajas para la agricultura y el comercio, cuya población pasa de dos millones de almas, no sólo pueden formar un cuerpo de república, sino que deben hacerlo si quieren asegurarse en el goce de sus derechos y no estar expuestas a caer de nuevo bajo el yugo ignominioso en que han gemido por espacio de tres siglos. ${ }^{26}$

Esta sería la esfera inicial de la formación de "un solo cuerpo de nación", sin desmedro de una posible unión futura con la federación de provincias que se había formado en la antigua Capitanía de Venezuela: "Es necesario constituir un cuerpo cuya inteligencia, cuya acción, cuyo imperio se extienda sobre todas las provincias del Reino, que de otro modo serán masas inertes y desorganizadas que caerán bajo los primeros golpes del invasor". Las veintidós provincias de la proyectada federación neogranadina le darían un tamaño ideal al nuevo Estado de la Nueva Granada, pues estados más grandes eran muy difíciles de gobernar, y este sería gobernado "por el sistema representativo y federativo, el único justo que se haya inventado y que afianza los derechos del hombre en sociedad".

Las ventajas de este pequeño estado, que no iría más allá del Istmo de Panamá y, en el sur, no más allá de Bracamoros, fueron expuestas por Camacho en la carta decimonovena (Ibagué, 12 de abril de 1812) y fueron las siguientes:

- Inspección más perfecta del territorio nacional

- Gobiernos de temporalidad más limitada

- Influencia del pueblo en el gobierno y mayor democracia

- Administración pública repartida entre más personas

25 Carta decimosexta citada, Gazeta de Cartagena de Indias, No. 15 y 16, julio 23 y 30, 1812.

26 Carta decimoséptima: "Que las provincias comprendidas bajo el antiguo régimen en el Virreinato de la Nueva Granada pueden componer una federación” (Ibagué, 30 de marzo, 1812), Gazeta de Cartagena de Indias, no. 17, 6 de agosto, 1812. 
- Mayor protección de los derechos del ciudadano

- Mayor conocimiento personal de los estadistas

- Legislación más perfecta

- Mayor civilización

Camacho siempre fue partidario de la conservación de la unidad de las provincias legadas por el régimen político anterior a la Nueva Granada, y se opuso a la secesión de pueblos para la formación de nuevas provincias. El ejemplo de los Estados Unidos de América le enseñaba que no convenía permitir la formación de nuevos estados dentro de los estados preexistentes:

Importa mucho que los pueblos reconozcan los antiguos centros [de las provincias], y no dar motivo a discusiones domésticas en estos críticos momentos en que nos debemos unir del modo más concertado y armonioso para resistir a los comunes enemigos, que hallarían en estas discordias un pretexto especioso para desacreditar la más grande y noble empresa que jamás pudieron concebir los mortales ... Debemos respetar las antiguas divisiones, y no destruir en vez de edificar, como pretenden algunos. ${ }^{27}$

En los sistemas federales existían tesoros de la Unión y además tesoros de cada una de las provincias, repartidas las contribuciones de los ciudadanos según una determinada razón; mientras que en los sistemas centrales toda la masa de los caudales se concentraba en un solo tesoro. Era entonces más adecuado el sistema federal, pues aquí las contribuciones de los ciudadanos se invertían en las provincias, reservándosele al tesoro de la Unión solo la parte requerida por las necesidades comunes. Esta distribución de las contribuciones era más justa, pues aseguraba a los ciudadanos la resolución de sus necesidades comunes y solo dejaba al gobierno general lo necesario para la defensa externa común.

Camacho libró en Santa Fe, desde finales de 1810 y a lo largo de 1811, una abierta lucha contra los abogados que, declarándose apoderados de los pueblos de Sogamoso, Chiquinquirá y la Villa de Leiva, intentaron obtener representación ante el primer congreso general del Reino que se instaló el 22 de diciembre de 1810. Como al siguiente día fue admitido el doctor Emigdio Benítez como "representante de la pretendida provincia de Sogamoso", Camacho se negó a presentar sus credenciales y alegó que no admitiría que se erigieran en provincia "unos pueblos que constituyen esencialmente y por límites que ha establecido la naturaleza, la antigua y respetable provincia de Tunja, que debe sostener su integridad en el más alto tono". ${ }^{28}$ Citado el 7 de enero de 1811, para que se posesionara en el Congreso, Camacho advirtió que gestionaría la expulsión de "todo representante que no fuese de provincia conocida por tal al tiempo de la revolución y, señaladamente, el de Sogamoso, que no debía subsistir por los motivos alegados".$^{29}$

Ante la resistencia del Congreso, no se posesionó de su representación, obteniendo el respaldo del Cabildo de Santa Fe.

27 Carta vigésima: "Sobre lo mismo: Que los estados pequeños se gobiernan mejor que los grandes", Gazeta de Cartagena de Indias, no. 33, 26 de noviembre, 1812 y no. 35, 10 de diciembre, 1812.

28 Carta de Joaquín Camacho al presidente y miembros de la Junta Suprema Provincial de Tunja informando que fue admitido como representante de la provincia de Sogamoso el Dr. Don Emigdio BENÍTEZ. Santafé, 24 de diciembre, 1810.

29 Carta de Joaquín Camacho al presidente y demás miembros de la Junta Suprema de la provincia de Tunja relatando las vicisitudes de su recepción en el contexto de la previa aceptación del diputado de Sogamoso en el Congreso. Santafé, 8 de enero, 1811. 
Como se sabe, el primer congreso del Reino terminó disolviéndose por sus contradicciones internas, abriéndose entonces dos opciones políticas enfrentadas: la del Estado de Cundinamarca, con pretensiones de mando sobre todas las provincias del Reino, y la del Congreso de las Provincias Unidas, cuyo pacto de federación les dejaba a salvo su autonomía para organizarse como estados. El balance de la primera pugna de las cabeceras provinciales con los pueblos que se les separaron temporalmente fue presentado por Camacho en los siguientes términos:

Todavía tendremos que sufrir mucho por las pretensiones de los lugares que rehúsan reconocer sus antiguas capitales. Por más que se les diga que las demarcaciones territoriales entre pueblos unidos no se pueden alterar sin el consentimiento universal porque cualquiera variación de los límites se hace sentir en la masa de la sociedad, ellos afectan no comprender este principio y, abandonándose al consejo de las pasiones, sacrifican el bien público a sus intereses particulares, mal entendidos y calculados, porque el mal causado al cuerpo político tarde o temprano se ha de experimentar en cada uno de los individuos. La disolución del Estado ha de ser una consecuencia precisa de estos extravios. Y si no formamos un todo, si las fuerzas comunes no se dirigen por un mismo espíritu, ¿cómo nos defenderemos de nuestros enemigos cuando no nos entendemos unos con otros y todos seguimos distintos rumbos? Estas verdades han resonado en nuestras asambleas y papeles públicos, pero el hado del Reino parece que se opone a su organización. ${ }^{30}$

Los dirigentes de las provincias de Cartagena y de Tunja, acudiendo a destacamentos armados, consiguieron el retorno de los pueblos separados temporalmente y les ofrecieron representación en sus colegios constituyentes.

\section{El primer escudo de las Provincias Unidas de la Nueva Granada}

Es bien conocido por la historiografía colombiana el escudo que fue adoptado por el Congreso de las Provincias Unidas después de su instalación en Santa Fe, una vez que Cundinamarca fue incorporado por las fuerzas acaudilladas por Simón Bolívar. Fue adoptado por la ley del 14 de julio de 1815 con un diseño de cuatro cuarteles en los que figuraban el Chimborazo, el cóndor con una garra levantada, la cascada del Tequendama y el istmo de Panamá con dos barcos a sus lados. Por sobretodo llevaba una granada abierta, por timbre un arco y una aljaba con flechas en aspa, y por orla en contorno una guirnalda hecha de granadas y ramas entrelazadas. La divisa, puesta en círculo, rezaba "Provincias Unidas de la Nueva Granada". Una flecha vertical de sable completaba la composición, saliendo por detrás de la parte superior de los cuarteles.

Pero lo que aún no se desentraña es el primer escudo que tuvo este Congreso en sus sedes de la Villa de Leiva y Tunja, entre octubre de 1812 y finales de 1814. El diseño se basaba en dos círculos concéntricos, en cuyo interior aparecen dos cornucopias que vierten en la parte superior monedas marcadas con una cruz (en otra versión vierten frutos y espigas de trigo y maíz), un par de manos entrelazadas y una saeta cuya punta está dirigida hacia la parte inferior, y en cuyo cabo sostiene un gorro frigio. El lema que circunda al círculo interior reza: RES. NEO-GRANAT. JUNGIT OPES FOEDUSQ FERIT, TUM LIBERA FATI. ${ }^{31}$ La fuente de este lema es el verso 154 del libro décimo de La Eneida, la obra del escritor

\footnotetext{
30 Carta de Joaquín Camacho a la Junta de Tunja argumentando contra la separación de los pueblos respecto de sus antiguas provincias y comunicando la llegada de los representantes de Antioquia y de Cartagena al Congreso. Santafé, 6 de abril, 1811.

31 "Escudo provisional de la Patria hasta 1813, grabado de Peregrino Rivera", Colombia Ilustrada, no. 13, 208.
} 
latino Publio Virgilio Marón, cuyo texto original dice: Tarchon Jungit opes foeduque ferit; tum libera fati (Tarcón junta sus fuerzas y hace un pacto [con Eneas], con lo cual se hace libre [de una prohibición del hado que hasta entonces le había impedido entrar a la contienda]). ${ }^{32}$ El verso aparece en un momento crítico de la guerra que dirigía Eneas, caudillo de los troyanos que habían invadido el Lacio, contra los rútulos. En medio de los fieros combates, a medianoche navegó Eneas hacia el campamento de Tarcón, el rey de los etruscos, para pedirle su ayuda. Tarcón accedió de inmediato y reunió su gente, pues esta demanda le había dejado en libertad respecto de una predicción del hado, que había vaticinado que los etruscos solo podrían entrar a la guerra bajo la conducción de un jefe extranjero, y enseguida navegó con Eneas al teatro de los combates. Curiosamente, la popa de la nave en que navegaron de regreso bajo el comando de Eneas tenía leones frigios uncidos a su cara (Phrygios subjuncta leones), y este escudo del Congreso adoptó un gorro de los frigios.

La persona que diseñó este escudo seguramente había estudiado en uno de los colegios mayores de Santafé, pues era en las cátedras de Gramática Latina en las que se leía y traducía a Virgilio, junto a Cornelio Nepote, Fedro, Cicerón, Tito Livio, Tácito y Ovidio. Debió recordar la angustia de Eneas al solicitar el apoyo de los etruscos de Tarcón y el impacto que esta alianza había tenido sobre la guerra que sostenía contra los rútulos para poder establecerse en el Lacio, y entonces decidió transformar el verso 154 del libro décimo, empleando la lengua latina, en el lema "Re[s]pública de la Nueva Granada. Junta sus fuerzas, pacta una alianza, y se hace libre". Esa persona era además un profundo conocedor de la opción política elegida por las provincias neogranadinas que firmaron el Acta de Federación (27 de noviembre de 1811), y además con la suficiente erudición como para poder comparar las dos situaciones históricas e identificar su similitud.

Entre los once diputados que permanecieron en la Villa de Leiva representando a siete de las provincias que firmaron el acta de la instalación del Congreso de las Provincias Unidas de la Nueva Granada el 4 de octubre de 1812, era José Joaquín Camacho quien reunía en sumo grado todos los atributos señalados. José María Salazar nos indicó su especial competencia en la lengua latina: "Hizo una buena colección de libros antiguos y modernos para el estudio de la historia, y aunque podía su feliz memoria repetir el texto original de Tito Livio y de Tácito, cultivó con provecho estos ramos que enseñan a conocer los hombres y negocios". La memorización de los textos latinos durante sus años pasados en el Colegio Mayor del Rosario correspondía al método peripatético de ese entonces, pues Camacho había tenido "la desgracia de ser lo que se llama un buen Ergotista, y aún de viciar su gran talento con el furor de frívolas disputas [aristotélicas]", hasta que su trato con los abogados payaneses del colegio seminario que dirigió Félix Restrepo le "despertó la razón", pasando "de peripatético a ser geómetra", pues "el nombre de Newton conjuró las fantasmas escolásticas". ${ }^{33}$ Queda aquí constancia, apenas como una hipótesis, su probable autoría del primer escudo del Congreso de las Provincias Unidas.

32 Publio Virgilio Marón, Eneida, trad. Rubén Bonifaz Nuño (México: UNAM, 2006), 220.

33 José María Salazar, “Doctor Joaquín Camacho”, 1819, obra citada. 


\section{CONCLUSIÓN}

Las veintitrés cartas políticas conocidas, escritas en Ibagué —entre comienzos de 1812 y abril de 1813- por José Joaquín Camacho y dirigidas a José Fernández Madrid, son la mejor fuente del discurso político de uno de los mayores publicistas del Congreso de las Provincias Unidas de la Nueva Granada. Su singular ilustración se formó en la lectura erudita de los libros clásicos del legado romano y del placer por el uso de lengua latina ${ }^{34}$ -Virgilio, Cornelio Nepote, Fedro, Terencio, César, Tito Livio, Quinto Curcio, Horacio, Plutarco, Cicerón y Ovidio-, así como en el estudio de las experiencias históricas de Roma, Francia y los Estados Unidos de América. La experiencia política acumulada antes de 1810 en la administración de tres corregimientos del Nuevo Reino de Granada Tocaima, Pamplona y El Socorro- fue enriquecida con los principios de Economía Política ${ }^{35}$ y la hermenéutica del Derecho Público.

Abogado de gran prestigio social, fue aclamado durante la noche del 20 de julio de 1810 para integrar la Junta Suprema que amaneció formada, pero pronto derivó hacia el proyecto de organización federal de las provincias del Reino. Los dirigentes de la Junta provincial de Tunja lo cooptaron para que ejerciera la representación de su provincia nativa ante el Congreso de las Provincias Unidas de la Nueva Granada, y como tal fue uno de los firmantes de su acta de instalación en la Villa de Leiva.

Las Cartas de Ibagué desarrollaron cuatro ideas básicas: la constitución de un pacto de defensa común de las provincias neogranadinas frente a los eventuales peligros exteriores, la necesidad de unificar una comunidad de intereses comerciales entre ellas, la crítica del intercambio comercial desigual que había existido en el anterior régimen, que empezó a llamar "sistema colonial", y la propuesta de construcción de una nueva organización política que hiciera de las antiguas provincias estados pequeños y manejables, asociados en una federación neogranadina que algún día pudiera llegar ante una liga de naciones en un congreso continental de América.

Desde la perspectiva de la República de Colombia que echaron a andar, desde finales de 1819, el general Simón Bolívar y Francisco Antonio Zea, el "nuevo sistema político" propuesto por Camacho era una utopía política, pues fue durante la década de 1820 que los publicistas liberales, y en especial los enemigos del general Antonio Nariño, desprestigiaron la experiencia de la Primera República neogranadina con el apodo de "patria boba". Era el tiempo de la gran unidad política que resultaría de unir las provincias que habían pertenecido a las audiencias de Caracas, Santa Fe y Quito, pretendiendo mostrar ricos y extensos territorios en las negociaciones internacionales para obtener el reconocimiento de la independencia respecto de la Corona de España. Esa era la perspectiva de José María Salazar en el Diario del Orinoco, cuando se calificaba de utópica la experiencia de las primeras repúblicas de la década de 1810.

Pero, como se sabe, el proyecto colombiano no pudo superar una década de existencia. Solo el carisma de Bolívar y la unidad de los ejércitos libertadores podían mantenerlo con vida, pero los abogados liberales de las antiguas audiencias resistieron ese proyecto y dieron paso a tres estados nacionales del mismo tamaño que predijo Camacho cuando convocó a organizar

34 En el Diario Político de Santafé de Bogotá, redactado por Camacho, se encuentran manchetas con textos en latín de Tito Livio en el prospecto y en la entrega no. 2.

35 José Joaquín Camacho publicó unos "Principios de economía política” en el Diario político de Santafé de Bogotá, en entregas sucesivas que comenzaron en el no. XXXVIII (1811): 151-152, 155-156, 162-163, 167-168, 170-171, 175-176, $181-182$. 
federaciones de las antiguas provincias indianas. Y la historia de los dos últimos siglos ha mostrado que la liga mundial de naciones era un proyecto realizable como medio para la pacificación del mundo. La federación continental de estados americanos es una realidad que llamamos Organización de Estados Americanos (OEA). A la larga, el discurso político de Camacho tuvo más fortuna que el ideal grancolombiano de Bolívar, cuya actualización por un reciente presidente venezolano sigue concitando la resistencia de los publicistas liberales.

El legado de Camacho también se extendió al texto de la Constitución del Estado de Tunja que fue aprobado el 9 de diciembre de 1811, pues uno de los dos proyectos que sirvieron de base a los debates fue escrito por él. La Declaración de Derechos y Deberes del hombre que antecede esta carta fue un ejercicio ecléctico realizado sobre la estructura de la Declaración francesa de 1793, de la cual se tomaron 18 artículos, pero además se tomaron 9 artículos del texto de 1795 y solamente uno, modificado, del texto de 1789 . El artículo $11^{\circ}$ es un collage de los textos de 1793 y 1795, y al menos diez artículos son "cosecha propia" de los constituyentes tunjanos. En general, se adoptó un régimen republicano, sin declarar abiertamente la desobediencia al rey cautivo. El valor de esta carta es su precocidad política, en el contexto americano, pues fue un reflejo de la rápida decisión de buena parte de la dirigencia de las provincias del Nuevo Reino de Granada a favor del orden republicano.

La calidad de la ilustración de José Joaquín Camacho, un publicista de la opción federal y republicana que tuvo vocación de estadista, es un buen ejemplo de la calidad política de la dirigencia de la Primera República. En medio de las vicisitudes de los duros enfrentamientos políticos y militares con los dirigentes del Estado de Cundinamarca, condujo la nave del gobierno general que se consolidó en las provincias que declararon la independencia respecto de la monarquía de los Borbones españoles, sorteando los escollos e innovando en todo cuanto estuvo a su alcance, pagando con la vida sus acciones políticas.

\section{FUENTES}

Cartas escritas por José Joaquín Camacho:

Cartas primera a cuarta, publicadas en El Argos Americano, Cartagena, enero, 1812.

Carta quinta: "Que en el comercio externo se versa el interés general de las Provincias" (Ibagué, 16 de enero, 1812), Gazeta de Cartagena de Indias, no. 3, 30 de abril, 1812.

Carta sexta: “Derechos de entrada y salida. Que los productos de la moneda que circula en el Reino deben ser comunes" (Ibagué, 22 de enero, 1812), Gazeta de Cartagena de Indias, no. 3, 30 de abril, 1812 .

Carta séptima: "Sigue hablando sobre la ley de la moneda" (Ibagué, 28 de enero, 1812), Gazeta de Cartagena de Indias, no. 5, 14 de mayo, 1812.

Carta octava: "Sistema general de política", Ibagué, 4 de febrero, 1812.

Carta nona: "Continúa el mismo asunto", Ibagué, 10 de febrero, 1812.

Carta décima en Gazeta de Cartagena de Indias, no. 7, 1812.

Carta undécima: "Las sociedades independientes no evitan la destrucción de la especie", Ibagué, 22 de febrero, 1812.

Carta duodécima: "Se explana el proyecto de Unión de las Naciones", Ibagué, 28 de febrero, 1812. 
Cartas decimotercera y decimocuarta, en Gazeta de Cartagena de Indias, no. 11 y 12, 1812.

Carta decimoquinta: “Uniformidad de pesos y medidas”, Ibagué, 18 de marzo, 1812.

Carta decimosexta: "Importa que cuanto antes se formen las federaciones americanas", Ibagué 24 de marzo, 1812.

Carta decimoséptima: "Que las provincias comprendidas bajo el antiguo régimen en el Virreinato de la Nueva Granada pueden componer una federación", Ibagué, 30 de marzo, 1812.

Carta decimoctava: "Que los Estados pequeños se gobiernan mejor que los grandes", Ibagué, 6 de abril, 1812.

Carta decimonona y vigésima: “Sobre lo mismo", Ibagué, 12 y 18 de abril, 1812.

Carta vigésimotercera, “Riqueza del país”, Ibagué, 4 de septiembre, 1812.

Cartas dirigidas al presidente de la Junta provincial de Tunja, Juan Agustín de la Rocha, 1811-1812.

Publicadas por Martínez Garnica, Armando, Gutiérrez Ardila, Daniel e Isidro Vanegas Useche, José Joaquín Camacho. Biografía y documentos de su pensamiento y acción política en la Revolución de Independencia. Tunja: Academia Boyacense de Historia, 2010.

http: / / www.google.com.co/ url? sa=i\&rct=j\&q=\&esrc=s\&source=images\&c$\mathrm{d}=\& \mathrm{cad}=\mathrm{rja} \& \mathrm{uact}=8 \& \mathrm{ved}=0 \mathrm{CAcQjRw} \& \mathrm{url}=\mathrm{http} \% 3 \mathrm{~A} \% 2 \mathrm{~F} \% 2 \mathrm{Fes}$. wikipedia. org\%2Fwiki\%2FJos\%25C3\%25A9_Joaqu\%25C3\%25ADn_Camacho\&ei=w158VI-HJIedgw T8m4PwDA\&bvm=bv.80642063,d.cWc\&psig=AFQjCNEUmQY2_TJNvrV58bkhreyO4XrS $0 \mathrm{w} \& u s t=1417523263824216$

\section{REFERENCIAS}

Gómez Hoyos, Rafael. “Joaquín Camacho, teórico del Derecho Público y de la Economía”, La revolución granadina de 1810. Ideario de una generación y de una época, 1781-1821. Bogotá: Temis, 1962.

Martínez Delgado, Luis. Noticia biográfica del prócer don Joaquín Camacho. Documentos. Bogotá: Academia Colombiana de Historia, 1954.

Martínez Garnica, Armando, Daniel Gutiérrez Ardila e Isidro Vanegas Useche, eds. José Joaquín Camacho. De lector ilustrado a publicista republicano (1807-1815). Bogotá: Universidad Externado de Colombia, 2011.

Martínez Garnica, Armando. "El discurso político de José Joaquín Camacho y Lago". Revista Historia de la Educación Latinoamericana. Vol. 16 No. 23 (2014): 


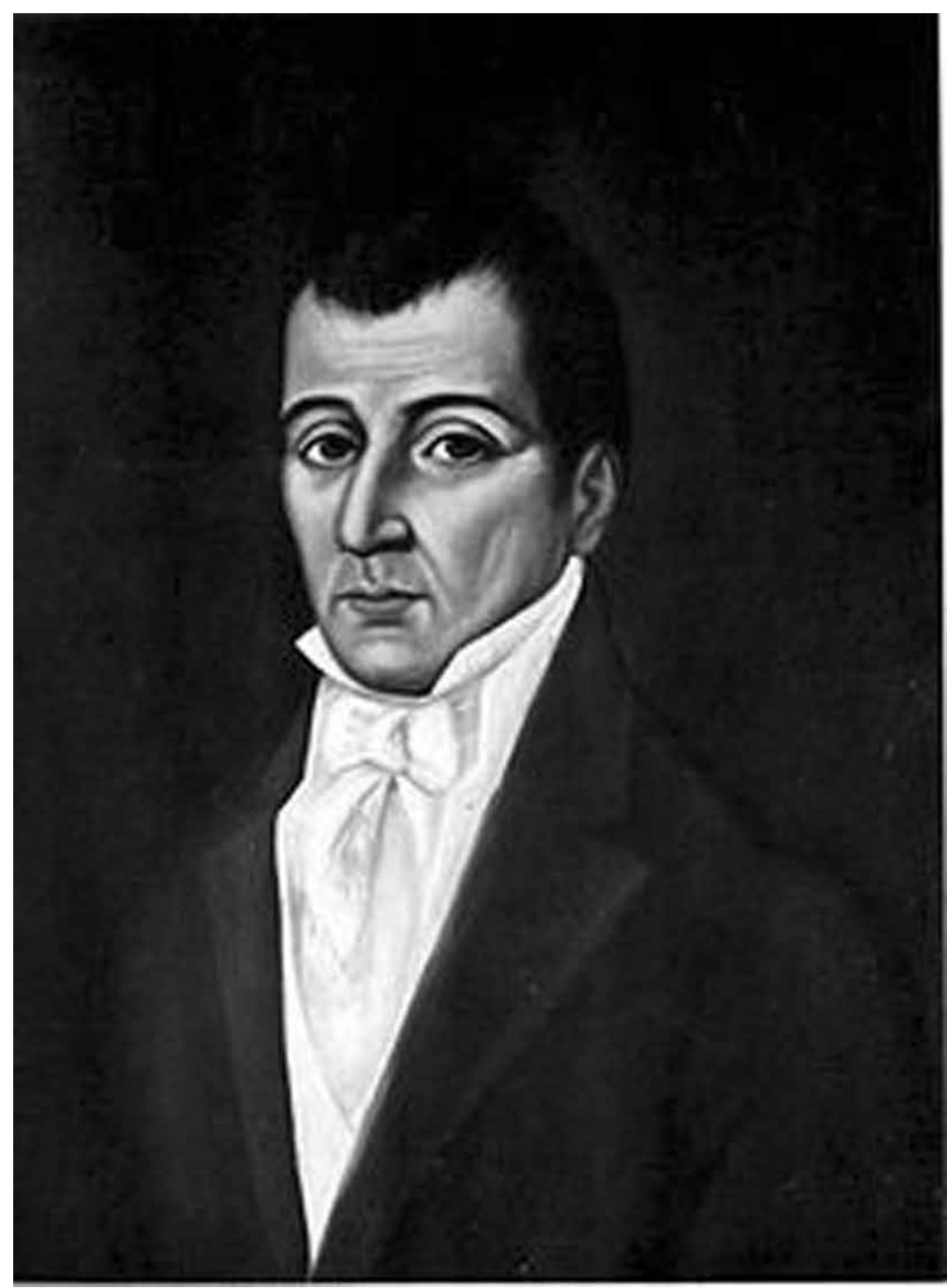

http://es.wikipedia.org/wiki/Jos\%C3\%A9_Joaqu\%C3\%ADn_Camacho

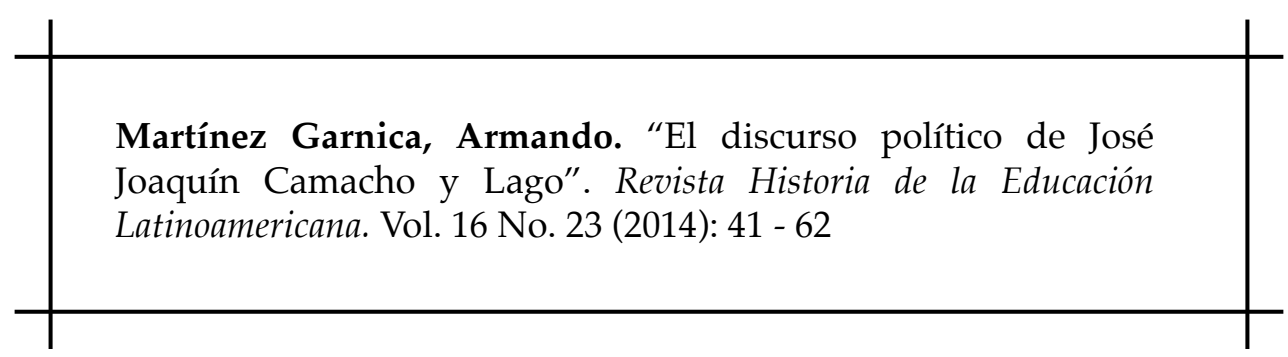

